ARTICLE

\title{
Proactive personality and job performance of athletic coaches: organizational citizenship behavior as mediator
}

\author{
Chia-Huei Hsiao ${ }^{1} \&$ Fong-Jia Wang ${ }^{2 凶}$
}

\begin{abstract}
Research has suggested that coaches who possess a proactive personality have greater job performance. However, contextual factors that may serve as behaviors conditions have received insufficient attention in the research. Accordingly, this study proposed organizational citizenship behavior as a mediation in the positive relationship between proactive personality and job satisfaction. We have 91 paired, completed questionnaires which formed the basis of the data analysis. Our results suggest that significant correlation between proactive personality, job performance, and OCB. Additionally, OCB mediated between proactive personality and job performance. Our findings provide strong evidence that a high degree of proactive personality among sports coaches has a significant and crucial influence on their OCB and job performance.
\end{abstract}

\footnotetext{
${ }^{1}$ Department of Leisure and Sport Management, National Taipei University, New Taipei City, Taiwan. ${ }^{2}$ Department of Physical Education, National Taiwan

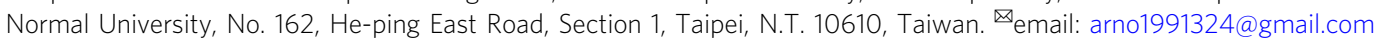




\section{Introduction}

thletic classes are an important component of education policies established by the government to cultivate athletes. Although studies on athletic classes have received considerable attention, they focus more on athletes than on the systems and personnel put in place to support them (Chan and Chen, 2010; Chen and Chen, 2011; Cunningham and Ahn, 2018). Studies of organizational citizenship behavior (OCB) in the context of sports have found that OCB is significantly correlated with athletic coaches' leadership behaviors, athletes' satisfaction, team cohesion, and other variables (Aoyagi et al., 2008; Choi et al., 2007; Kent and Chelladurai, 2001; Kim et al., 2018). Therefore, positive organizational behavior underscores human strengths and psychological capacities, which are situational and developmental in nature (Parker et al., 2010). This perspective is aligned with an outlook that assumes the malleability of employees' state-like capacities, which are deemed manageable and transformable for performance improvement (Kim et al., 2018). It is well suited to today's fast-paced and unpredictable environment because, under such conditions, employees are constantly pressured to develop and adjust their expertise in accordance with various demands by the organization. Focusing on state-like positive capacities in the workplace motivates the selection of positive organizational behavior in this model, with the view of creating new opportunities for sports coaching development and performance management for sport organizations. One of these variables, organizational operation relationships, relates to the ways in which basic needs, such as emotional support, protection, and care, are satisfied through social interaction within an organization, which can take the form of emotional attachment among organization members (Chu et al., 2012). When such attachment exists within an organization, members show a willingness to sacrifice their interests to maintain relationships. This, in turn, helps to sustain relationships and increase the degree of dependency. Further, it enhances the degree of satisfaction among those within the organization and reduces turnover. In other words, when the organization appears to be highly dependent on the behavior of others, individuals are willing to sacrifice self-interests for the sake of the relationship (Bretherton, 1992; Lin et al., 2012).

Theoretical background. Organization members with proactive personalities tend to draw on positive emotions and leverage factors, such as personal values, knowledge, and skills to motivate themselves (Parker et al., 2010). Those with a tendency for proactive personality are unlikely to feel constrained by limitations and are often able to change constricting circumstances (Bateman and Crant, 1993; Campbell, 2000; Crant, 1996; Grant, 2000; Greenglass, 2002; Miao and Shih, 2013). Such individuals also regard perceived crises or demands as opportunities for personal growth and deal with stress proactively. Additionally, they develop organizational attachments and interdependencies, which provide them with the resources and space they need to achieve better work outcomes (Seibert et al., 1999). Proactive personality traits affect the performance of organization members at different levels of OCB, such as organizational identity and proactive coworker support (Seibert et al., 2001). Since its introduction into the literature, the concept of proactive personality has circulated in organizational behavior research and has been widely applied in studies on industrial and organizational psychology and workplace behavior. Researchers in the field have published studies examining the influences of proactive personality on factors, such as work outcomes, job pressure, attitudes toward work, job satisfaction, and OCB (Bateman and Crant, 1993; Chin et al., 2008; Cunningham and Ahn, 2018; Yeh and Lin, 2007).
Being proactive, rather than passive, can be an essential way to cultivate OCB because proactivity concerns making things happen and striving to improve one's situation (Miao and Shih, 2013). For the past two decades, the concept of proactive personality has been widely applied in research on organizational behavior, and a number of studies and meta-analysis reviews support the use of proactive personality to predict work outcomes (Cammann et al., 1979; Chin et al., 2008; Crant, 1996; Miao and Shih, 2013; Parker et al., 2006). Researchers have found that proactive personality is associated with beneficial innovation, entrepreneurship, organizational commitment, and job satisfaction (Greenglass, 2002; Lu and Kuo, 2016; Parker et al., 2006). Yet, surprisingly, little research has investigated how athletic coaches with proactive traits might influence OCB and job performance. In this regard, we adopted the proactive motivation model as a framework for the current study. The proactive motivation model assumes that individual proactivity is a goal-driven process ( $\mathrm{Lu}$ and Kuo, 2016; Miao and Shih, 2013; Parker et al., 2006).

In the field of organizational behavior, the concept of OCB has received substantial attention from practitioners and researchers as a prototypical positive organizational behavior (Parker et al., 2010) because such behaviors have a beneficial influence on individual and organizational effectiveness (Miao and Shih, 2013). However, there has been little research (Kim et al., 2018; $\mathrm{Lu}$ and Kuo, 2016) regarding OCB and the relationships between OCB and other variables in sport, despite its potential impact on team performance. Given this background, the purpose of the current study was to investigate $\mathrm{OCB}$ as a mediation efface in the context of sport. Exhibiting traits like a stable personality, those with positive organizational behavior adopt developmentally positive constructs to improve human and organizational conditions (Bateman and Crant, 1993; Kim et al., 2018). In addition, positive organizational behavior impacts performance, and endows individuals with an ability to adapt to different situations. In light of all of this, the influence of proactive personality on organizational effectiveness is a good predictor of work outcomes, at least in those professions where it has been examined (Chin et al., 2008; Seibert et al., 1999). Previous studies on proactive personality and leadership behavior have mainly examined the individual personality traits of enterprise leaders (Bateman and Crant, 1993; Crant, 1996; Dirks and Ferrin, 2002; Grant, 2000; Greenglass, 2002; Lu and Kuo, 2016; Miao and Shih, 2013), while only a few studies have discussed the individual personality traits of subordinates and their influence on organizational work outcomes or team effectiveness. Our study helps fill this gap.

Proactive personality and job performance. In a discussion of the emergence, application, and future of organizational behavior research in sport, Love and Kim (2019) specifically identified OCB as an area deserving further attention to better understand psychosocial dynamics in sport teams. Many researchers in the field of sport management have applied various constructs of organizational behavior, such as leadership, organizational support, organizational justice, job satisfaction, and organizational commitment, to sport settings under the belief that such constructs should influence performance (Kim et al., 2018; Lu and Kuo, 2016). However, despite the important differences between sport organizations and organizations in other fields, many studies have been limited to simply explore relationship between single-aspect variable and OCB to the context of sport (Love and Kim, 2019). Specifically, our first study hypothesis (H1) states that proactive personality traits positively impact athletics coaches' job performance (see Fig. 1). 


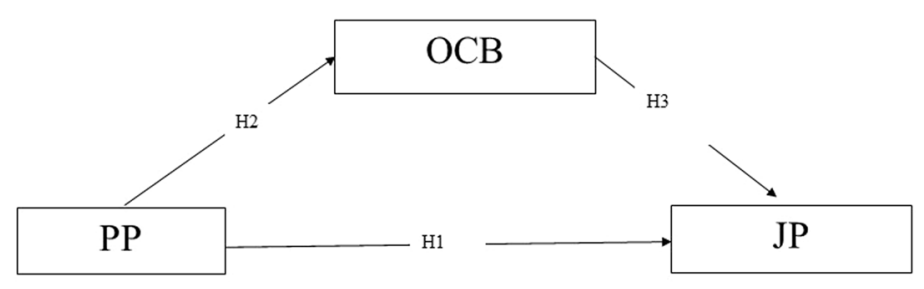

$\mathrm{PP}=$ proactive personality $\mathrm{OCB}=$ organizational citizenship behavior; $\mathrm{JP}=$ job performance.

Fig. 1 Conceptual model. This figure is the proposed research model of this paper.

Proactive personalities and OCB. Within the culture of Chinese organizations influenced by Confucianism, subordinates must respect and follow the decisions of their bosses and supervisors (Chou et al., 2014). Thus, employees exposed to proactive personality tendencies will achieve better work outcomes and demonstrate greater OCB (Aoyagi et al., 2008; Chen et al., 2012). In other words, when members of an organization sense that their supervisors have proactive personalities, they do their best to perform their tasks and exhibit behaviors in a way that is most beneficial to the organization. The concept of OCB has received attention from many organizational behavioral scholars (Chen, 2008; Eisenberger et al., 1986; Ji et al., 2008), and most studies have confirmed the correlation between OCB and work outcomes (Eisenberger et al., 1990; Hochwarter et al., 2003; Preacher and Hayes, 2004; Viswesvaran et al., 1996; Wayne et al., 2002). Past studies have shown that OCB is related to aspects of service delivery and participation (Graham, 1991; Moorman et al., 1998). These studies characterize job requirements in terms of workload and the staffs OCB in terms of the extent of organizational support in the workplace (Ackfeldt and Coote, 2005; Han et al., 2009; House et al., 1988; Li and Wan, 2007; Lin et al., 2012). While such studies have been fruitful, many factors affecting job performance in the Chinese context of athletic coaches (House et al., 1988; Lin et al., 2012) require further examination (Cunningham and Ahn, 2018). Thus, our second hypothesis (H2) states that the more athletic coaches exhibit proactive personalities, the greater the impact of their OCB (see Fig. 1).

OCB mediates between proactive personality and job performance. Previous studies have also found that organizational effectiveness can be impacted at many levels and that OCB affects work outcomes in terms of factors, such as organizational commitment, job satisfaction, loyalty, intention to quit, trust, and happiness (Aoyagi et al., 2008; Arshadi, 2011; Choi et al., 2007; Dirks and Ferrin, 2002; Han et al., 2009; Kim et al., 2018; Miao and Shih, 2013). Supervisors have always played a critical role in an organization's operations, in that they affect employees' attitudes and behaviors at work and are instrumental in achieving organizational goals and effectiveness (Chou et al., 2014; Ji et al., 2008). Supportive supervisors and a high level of perceived support from the organization positively impact work outcomes (Eisenberger et al., 1986; Hochwarter et al., 2003; Parker et al., 2010; Tian et al., 2009; Viswesvaran et al., 1996). Although this has been widely recognized, several issues have not yet been fully explored. For example, psychological changes that affect proactive personality traits in the organization's operational process are seldom discussed. Most studies related to Chinese organizations have neglected to discuss potential psychological changes of subordinates (Kim et al., 2018; Lin et al., 2017; Wayne et al., 2002). However, the influence of the organization's behavior on subordinates has always been a fairly important topic in the field of organizational behavioral research. In line with this, our study considered OCB as an important mediating factor. Specifically, our third hypothesis (H3) states that OCB mediates between proactive personality and job performance (see Fig. 1).

\section{Methods}

This study examined the relevant factors affecting work outcomes of sports coaches by collecting data with structured questionnaires. The main variables included proactive personality, job performance, and OCB. In addition, we collected demographic data, including gender and the sports coached by participants. Further, this study was approved to office of research and development National Taiwan University (ID number: 201505ES004) and confirming that informed consent was obtained from all participants guardians.

Participants and procedures. We randomly selected full-time accredited coaches from high school athletic classes near Taiwan and asked them to complete two sets of questionnaires. The sports team leaders (e.g., are these student athletes who perform the role of team captain or are they paid professionals who lead a team under a school athletic coach), and their coaches were paired to evaluate the coaches' work outcomes. We conducted tests in two phases and measured variables at intervals of 4 weeks to confirm their sequential relationships. We used the time segregation method to collect different variable data in different phases. The first phase of the questionnaire measured the independent variable (i.e., proactive personality) and collected demographic data. The second phase measured the mediator (OCB) and the dependent variable (job performance). At the same time, we performed a paired comparison of demographic variables to eliminate confounding factors. Questionnaire results were anonymized, and items were allocated randomly in the measurement tool design to avoid psychological interference in the responses.

The research objects of this study included 79 high school athlete classes in Taiwan with a total of 351 athletic coaches and 359 sports team leaders as research participants. The total number of paired comparison questionnaires was 351. After excluding invalid questionnaires, the final number of effective paired comparison questionnaires (i.e., paired comparison questionnaires where questionnaires from both phases were completely filled out) was 91 . We received completed sets of paired questionnaires (phases one and two) from 91 participants. As shown in Table 1, of the total number of coaches, 66 were male (71.4\%) and 25 females (26.4\%). Regarding the sports expertise represented by the participants, running (14 people, $15.4 \%$ ), followed by badminton (11 people, $12.1 \%)$, taekwondo (9 people, $9.9 \%)$, and basketball (7 people, $7.7 \%$ ), all sports items shown in Table 1.

\section{Measures}

Proactive personality scale. This study used the proactive personality scale from Seibert et al. (1999). We used a total of 10 items, such as "I will finish everything that is feasible to me regardless of the success rate" and "I am always looking for better practices". Each item was structured according to a 7-point Likert scale, from 1 
Table 1 Descriptive statistics analysis of study sports items.

\begin{tabular}{|c|c|c|}
\hline Item & Number & Percentage \\
\hline \multicolumn{3}{|l|}{ Gender } \\
\hline Man & 66 & 71.4 \\
\hline Female & 25 & 26.4 \\
\hline \multicolumn{3}{|l|}{ Sports items } \\
\hline Taekwondo & 9 & 9.9 \\
\hline Soft tennis & 3 & 3.3 \\
\hline Handball & 1 & 1.1 \\
\hline Badminton & 11 & 12.1 \\
\hline Volleyball & 4 & 4.4 \\
\hline Table Tennis & 1 & 1.1 \\
\hline Boxing & 5 & 5.5 \\
\hline Archery & 3 & 3.3 \\
\hline Running & 14 & 15.4 \\
\hline Judo & 4 & 4.4 \\
\hline Tennis & 5 & 5.5 \\
\hline Canoe & 1 & 1.1 \\
\hline Swim & 2 & 2.2 \\
\hline Martial arts & 1 & 1.1 \\
\hline Football & 5 & 5.5 \\
\hline Basketball & 7 & 7.7 \\
\hline Canoeing & 1 & 1.1 \\
\hline Baseball & 3 & 3.3 \\
\hline Tchoukball & 1 & 1.1 \\
\hline Weightlifting & 3 & 3.3 \\
\hline Woodball & 1 & 1.1 \\
\hline Tug-of-war & 1 & 1.1 \\
\hline Hockey & 2 & 2.2 \\
\hline Gymnastics & 1 & 1.1 \\
\hline Rugby & 1 & 1.1 \\
\hline Softball & 1 & 1.1 \\
\hline
\end{tabular}

(strongly disagree) to 7 (strongly agree). Using Cronbach's alpha, we calculated the internal consistency to be 0.83 .

OCB scale. This study used the OCB scale from Coleman and Borman (2000). We included a total of 27 items, such as "coaches are happy to assist other school members" and "coaches are willing to pay extra efforts and work hard". Each item adopted a 7-point Likert scale, from 1 (strongly disagree) to 7 (strongly agree). Internal consistency was calculated to be 0.98 using Cronbach's alpha.

Job performance scale. This study used the job performance scale from Thompson (2005). Six items, including working hours, work quality, attendance, professional expertise, and relationship between colleagues, were evaluated. A 6-point Likert scale, from 1 (very poor) to 6 (excellent), was adopted for all items. Internal consistency was calculated to be 0.88 using Cronbach's alpha.

Statistical analysis. Data processing and analysis took place in two stages. We first analyzed background variables of the sample population using descriptive statistics. Next we described the scores of all participant variables used in subsequent statistical analysis. Then, we examined correlations among variables using hierarchical regression analysis to test if organizational citizenship mediated between proactive personality and job performance. Therefore, we conducted multiple mediation analysis structural equation modeling (SEM) to test our hypotheses (Hayes, 2017). To clarify the relative contribution of the variables, a regression analysis was done. To answer questions concerning relationships between the variables tested, three Pearson

\begin{tabular}{lllllll}
\multicolumn{7}{l}{ Table 2 Correlations among study variables. } \\
& $\mathbf{M}$ & SD & Gender & PP & OCB & JP \\
\hline Gender & 1.36 & 0.77 & - & & & \\
PP & 5.49 & 0.77 & 0.12 & - & & \\
OCB & 6.03 & 0.91 & 0.09 & $0.21^{\star}$ & - & \\
JP & 5.33 & 0.70 & 0.18 & $0.29^{\star \star}$ & $0.45^{\star \star}$ & - \\
\hline$N=91$. & \\
$P P$ proactive personality, & OCB organizational citizenship behavior, JP job performance. \\
${ }^{*} P<0.05 ;{ }^{\star *} p<0.01$. & \\
\hline
\end{tabular}

product-moment correlations were calculated. First, we used regression analysis on the predictive explanatory power of proactive personality on job performance (H1); Second, we used regression analysis on the predictive explanatory power of proactive personality on OCB (H2); and Third, we used SEM to verify the OCB mediator effect $(\mathrm{H} 3)$. In addition, we used Baron and Kenny's mediator variable and verification steps. To test our mediation models, a script version of the SPSS PROCESS macro was adopted for the simple mediation analysis developed, and we tested estimated indirect effects. In addition, we conducted a bootstrapping analysis by resampling the dataset 1000 times to verify the total indirect effect. We adopted Baron and Kenny's four recommended criteria for the mediator examination. According to the first standard (a path), the independent variable has a direct effect on the mediator variable. The second standard requires that the mediator variable has an effect on the outcome variable after controlling for the independent variable (b path). In the third standard (c path), the independent variable performs a total effect on the outcome variable. Finally, the effect of the independent variable on the outcome variable becomes significantly smaller or non-significant after controlling for the mediator (i.e., direct effect; c' path). We used IBM SPSS version 22 and Amos version 20 for Windows for data analysis. The confidence level was set at 95\% $(p \leq 0.05)$.

\section{Results}

As shown in Table 2, proactive personality was positively related to OCB $(r=0.21, p<0.05)$ and job performance $(r=0.29, p<$ $0.01)$. Moreover, OCB was positively related to job performance $(r=0.45, p<0.01)$. These results showed that proactive personality, OCB, and job performance were positively correlated.

In the regression analysis, extreme values were removed. Additionally, collinearity problems and influential observations were identified. Inspection of residual plots and the cumulative normal probability plot ( $\mathrm{p}-\mathrm{p}$ plot) showed that residuals were distributed normally (Hayes, 2017). The regression results are shown in Table 2 and indicate that proactive personality had a significant relationship with job performance $(\beta=0.26, p<0.01)$; that is, the greater the proactive personality, the better the job performance. These results support our first hypothesis.

Table 3 shows the regression results, which indicate that proactive personality had a significant relationship with OCB ( $\beta=0.25, p<0.05)$; that is, the greater the proactive personality, the greater the OCB. These results support our second hypothesis.

Mediator analysis. Table 4 shows results of the mediator analysis, which indicate that $\mathrm{OCB}$ plays a mediating role between proactive personality and job performance. Additionally, the SEM model showed a satisfactory root mean square error of approximation, RMSEA $=0.11$, standardized root mean square residual, $\mathrm{SRMR}=$ 0.08 , goodness of fit index, GFI $=0.53$, adjusted goodness of fit index, $\mathrm{AGFI}=0.48$, non-normed fit index, $\mathrm{NNFI}=0.74$, and comparative fit index, $\mathrm{CFI}=0.75, \chi^{2} / \mathrm{df}=1924.89 / 857$. 


\section{Table 3 Linear regression analysis of proactive personality} of job performance.

PP

\begin{tabular}{llll}
\hline & B & SE $\boldsymbol{B}$ & $\boldsymbol{\beta}$ \\
\hline $\mathrm{JP}$ & 0.26 & 0.09 & $0.29^{\star \star}$ \\
$R^{2}$ & 0.09 & & \\
Adj $R^{2}$ & 0.08 & & \\
$F$ & $8.39^{\star \star \star}$ & & \\
$\mathrm{df}$ & $(1,89)$ & & \\
\hline
\end{tabular}

$N=91$.

$P P$ proactive personality, JP job performance.

${ }^{\star \star} p<0.01 ;{ }^{\star \star \star} p<0.001$

\begin{tabular}{|c|c|c|c|}
\hline \multicolumn{4}{|l|}{ PP } \\
\hline & B & SE $B$ & $\beta$ \\
\hline $\mathrm{OCB}$ & 0.25 & 0.12 & $0.21^{\star}$ \\
\hline$R^{2}$ & 0.05 & & \\
\hline $\operatorname{Adj} R^{2}$ & 0.04 & & \\
\hline$F$ & $4.28^{\star \star}$ & & \\
\hline $\mathrm{df}$ & $(1,89)$ & & \\
\hline
\end{tabular}

$N=91$.

$P P$ proactive personality, $O C B$ organizational citizenship behavior.

${ }^{\star} p<0.05 ;{ }^{\star \star} p<0.01$

To test our mediation models, a script version of the SPSS PROCESS macro was adopted for simple mediation analysis (Preacher and Hayes, 2004), and we tested for estimated indirect effect. In addition, we conducted a bootstrapping analysis by resampling the data set 1000 times to confirm the total indirect effect (Baron and Kenny, 1986). We adopted Baron and Kenny's (1986) four recommended criteria for the mediator examination. According to the first standard (a path), the independent variable has a direct effect on the mediator variable. The second standard requires that the mediator variable has an effect on the outcome variable after controlling for the independent variable (b path). In the third standard (c path), the independent variable performs a total effect on the outcome variable. Finally, the effect of the independent variable on the outcome variable becomes significantly smaller or non-significant after controlling for the mediator (i.e., direct effect; c' path).

The results of the mediator analysis to test the relationship among proactive personality (PP), $\mathrm{OCB}$, and job performance (JP) are shown in Table 4. Proactive personality (PP) had a significantly positive effect on OCB ( $a$ path: $B=0.20, \mathrm{SE}=0.10$, $t=1.67, p<0.05)$. Therefore, OCB had a significantly positive effect on job performance (JP) ( $b$ path: $B=0.48, \mathrm{SE}=0.15, t=$ $3.24, p<0.01)$, and proactive personality (PP) had a significantly positive effect on job performance (JP) ( $c$ path: $B=0.26, \mathrm{SE}=$ $0.09, t=1.85, p=<0.04)$. Moreover, the relationship between proactive personality and job performance diminished and became non-significant when OCB was controlled for ( $c^{\prime}$ path: $B=0.18, \mathrm{SE}=0.08, t=2.85, p<0.09$ ). The results indicated that OCB mediated the relationship between proactive personality and job performance (Baron and Kenny, 1986). The bootstrap results for indirect effect also confirmed that $95 \%$ of the estimates were between 0.28 and 0.41 , excluding zero. These results support our third hypothesis (see Table 5), supporting our expectations.

\section{Discussion}

The objectives of this study were to explore the relationship between organizational attachment, athletic coaches' proactive personality traits, and job performance, and to further explore the role of OCB as a moderator in this relationship. Using the definition and verification method of moderators proposed by Baron and Kenny (1986), we found that OCB played a mediating role in the relationship between proactive personality and job performance. These findings support the importance of organizational attachment in the process of developing the personality traits of successful sports coaches. Next, we discuss study results in terms of our three hypotheses.

Effects of proactive personality on job performance. The results showed that proactive personality was a powerful predictor of job performance; athletic coaches with more proactive personalities performed their jobs better. Based on the correlation analysis, a positive relationship was found among proactive personality, OCB, and work outcomes. Other studies (Chen et al., 2012; Hayes and Scharkow, 2013; Hochwarter et al., 2003; Preacher and Hayes, 2004), have also found that proactive personality and work outcomes are correlated. Thus, heads of athletics departments will value and promote a coach exhibiting proactive personality traits. In this way, proactive personality positively impacts job satisfaction and performance. Proactive personality traits are conducive to deliberate efforts of creativity, which help an individual achieve better performance, adapt to the work environment, and improve or enhance the organization's internal operations to achieve its goals (Parker et al., 2006).

Therefore, when a person with proactive personality contributes to the organization it also reinforces the attachment theory premise that when individuals feel attached to the organization, they are more willing to make sacrifices to improve the organization's performance (Conklin et al., 2009; Lin et al., 2012; Thompson, 2005). When the head of the physical education department offers coaches' positive attention, affirmation, and support, they will develop a high level of job satisfaction that will, in turn, drive them to be more dedicated to their work and improve work outcomes. Based on the above, the results of this study confirmed that proactive personality affects work outcomes through a number of factors, and that the extent to which a sports coach possesses proactive personality traits can predict professional outcomes.

Effects of proactive personality on OCB. Our results showed that proactive personality had significant explanatory power for OCB, whereby the more the coach exhibited traits of a proactive personality, the higher the coaches OCB. Past studies have shown that people with proactive personality tendencies are not constrained by external factors but rather take initiative and use coping strategies to change their circumstances when necessary (Bateman and Crant, 1993). Empirical research has found that people with a high degree of proactive personality more often go beyond the expectations or the requirements of their professional roles to satisfy their own high expectations (Rhoades and Eisenberger, 2002). Proactive personality breaks through dilemmas, alters the restricted environment and achieves the goals of the individual or the organization (Bateman and Crant, 1993; Parker et al., 2006). From this point of view, when a sports coach possesses higher proactive personality tendencies, they are more willing to perform the tasks with which the organization entrusts them. This also echoed the suggestion of Chang et al. (2009) that people with highly proactive personality will break through difficult situations, look for opportunities, demonstrate initiative, and persevere. Our results also showed that when athletic coaches 
Table 5 Mediator analysis effect on job performance.

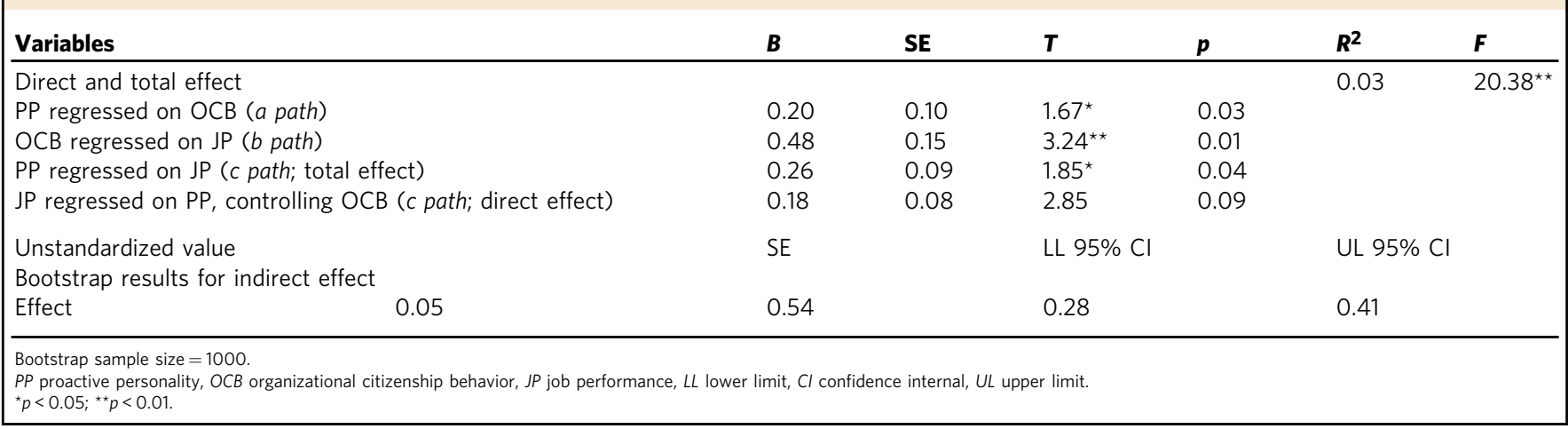

with proactive personality traits perceived higher OCB levels, their proactive tendencies could be strengthened, enhancing $\mathrm{OCB}$, and thus improving team outcomes. This is in line with the suggestion of Lin et al. (2012) that when members of an organization develop a sense of attachment, they are willing to sacrifice their own interests to maintain these relationships, which helps enhance job satisfaction within the organization and reduce turnover. Accordingly, coaches with proactive personality traits can help improve OCB and work efficiency.

OCB as mediator on proactive personality and job performance. Consistent with our third hypothesis, our analyses showed that OCB had a partial mediating effect on proactive personality and job performance. In other words, the better the coaches' OCB, the higher their job performance. By improving OCB athletic coaches generated additional resources that helped them perform well in the face of challenging circumstances. Thus, OCB and job performance were positively correlated. Our results support the conclusions of other studies that show OCB to have a significant mediating effect on team performance and job performance (Chang et al., 2009; Dirks and Ferrin, 2002; Hayes, 2009; Moorman et al., 1998). Based on our results, we found that excellent job performance and work outcomes of athletic coaches are generated by a high degree of perceived organizational support from physical education team leaders and school authorities, who are thus capable of encouraging the development of proactive personality traits and generating a high degree of workplace satisfaction. From this point of view, proactive care and assistance from physical education team leaders and school authorities can motivate sports coaches to demonstrate proactive personality traits, thereby enhancing their OCB and encouraging high performance. Overall, students with higher proactive personalities will have more OCB, which in turn should lead to better job performance. From this point of view, proactive care and assistance from sports team leaders and school authorities can motivate athletic coaches to demonstrate proactive personality traits, thereby enhancing their OCB and encouraging them to perform more effectively.

\section{Conclusions}

This study investigated the direct impact of a coach's proactive personality tendency on job performance and OCB and sought to determine whether OCB mediates between proactive personality and job performance. Our findings provide strong evidence that a high degree of proactive personality among sports coaches has a significant and crucial influence on their OCB and job performance. In addition to corroborating results from previous studies on proactive personality and leadership, our findings verified that other variables, specifically proactive personality and $\mathrm{OCB}$, have a definitive, positive effect on coaches' performance. This study explored the benefits of proactive personality traits among athletic coaches from the perspective of organizational attachment theory. With rigorous theoretical support, the study delved into the organizational behavior and work outcomes of sports coaches in athletic classes and expanded the scope of application of organizational behavior research. The results of the current study indicate that coaches engage in a wide variety of leadership styles that may be considered OCB. Some of these activities (e.g., getting extra practice, motivating and supporting teammates, giving good effort, recruiting, exceeding academic expectations, performing community service, and being social with fans) share clear connections with facets of OCB identified in nonsport settings. Specifically, understanding the unique nature of OCB in sport can help coaches and administrators better develop team policies and practices that can encourage athletes to focus their efforts on the most valuable types of $\mathrm{OCB}$, while avoiding undue pressure that may lead to overtraining and burnout.

Future research and suggestions. This method of investigation is not without limitations. First, the self-reported data might inflate the relationship among our research variables because of common method variance. Future research should address this issue by using objective measurements or field experiments. Second, we did not investigate the issue of time in the current study. Because there was no specific guidance on when changes in the variables arose, future studies should use optimal time-lagged intervals, which would be helpful to proximally capture the stability and changes of key constructs. Future research could exploit the issue of time to explore the effect of proactive personality on the dynamic changes in job satisfaction.

In general, current study results provide physical education team leaders, departments, and educational authorities with important implications. Based on our findings, we suggest that physical education team leaders, departments, and educational authorities should foster an organizational atmosphere conducive to the development of proactive personalities in athletic coaches. To accomplish this, they should provide their coaches with training resources and opportunities, such as professional and continuing education courses. Offering ample assistance with career planning and development could also help imbue coaches with a positive perspective with regard to the organization. This, in turn, will motivate athletic coaches to enhance their OCB and improve job performance. Therefore, it is suggested that physical education team leaders, departments, and educational authorities consider proactive personality traits as an important factor in the selection of athletic coaches. 


\section{Data availability}

Owing to privacy reasons, the datasets analyzed during the current study are not publicly available but are available from the corresponding author on reasonable request.

Received: 13 November 2019; Accepted: 11 February 2020;

Published online: 28 February 2020

\section{References}

Ackfeldt A-L, Coote LV (2005) A study of organizational citizenship behaviors in a retail setting. J Bus Res 58(2):151-159. https://doi.org/10.1016/S0148-2963 (03)00110-3

Aoyagi MW, Cox RH, McGuire RT (2008) Organizational citizenship behavior in sport: relationships with leadership, team cohesion, and athlete satisfaction. J Appl Sport Psychol 20(1):25-41. https://doi.org/10.1080/10413200701784858

Arshadi N (2011) The relationships of perceived organizational support (POS) with organizational commitment, in-role performance, and turnover intention: mediating role of felt obligation. Procedia - Soc Behav Sci 30:1103-1108. https://doi.org/10.1016/j.sbspro.2011.10.215

Baron RM, Kenny DA (1986) The moderator-mediator variable distinction in social psychological research: conceptual, strategic, and statistical considerations. J Pers Soc Psychol 51(6):1173-1182

Bateman TS, Crant JM (1993) The proactive component of organizational behavior: a measure and correlates. J Organ Behav 14(2):103-118. https://doi.org/ $10.1002 /$ job.4030140202

Bretherton I (1992) The origins of attachment theory: John Bowlby and Mary Ainsworth. Dev Psychol 28(5):759-775

Cammann C, Fichman M, Jenkins D, Klesh J (1979) The Michigan organizational assessment questionnaire. University of Michigan, Ann Arbor, Unpublished manuscript

Campbell DJ (2000) The proactive employee: managing workplace initiative. Acad Manag Perspect 14(3):52-66. https://doi.org/10.5465/ame.2000.4468066

Chan CC, Chen SC (2010) A study of implementing the effective strategy for athletic coaches in schools. Q Chin Phys Educ 24(4):112-119

Chang HT, Chi NW, Liou JW, Lin ML (2009) Exploring the effects of proactive personality, social value orientation and customer justice perception on individual social capital. NTU Manag Rev 20(1):99-129

Chen CC (2008) Test of mediating model linking perceived organizational support and job performance. J Manag Bus Res 25(3):309-331

Chen JW, Lu L, Hsu YY (2012) The associations among job demands, work resource and work attitudes: conscientiousness and proactive personality traits as moderators. J Hum Resour Manag 12(1):23-49

Chen YF, Chen JF (2011) Learning and advanced education of high school students in athletic class: a perspective of ecological systems. Phys Educ J 46(4):443-457

Chin JT, Lee HW, Wang HY (2008) The relationship between big five model and job performance. Oper Manag Rev 4(2):1-9

Choi J, Sagas M, Park S, Cunningham GB (2007) Transformational leadership in collegiate coaching: the effects of transformational leadership on job satisfaction, organizational commitment, and organizational citizenship behavior. Int J Sports Manag 8(4):429

Chou WJ, Chaeng BS, Lien YH (2014) Authoritarian leadership: a review and agenda for future research. Chin J Psychol 56(2):165-189

Chu KK, Yu SY, Pan SY (2012) The influence of organizational attachment to organizational climate and organizational performance in image business district. J Hum Resour Manag 12(1):51-73

Coleman VI, Borman WC (2000) Investigating the underlying structure of the citizenship performance domain. Hum Resour Manag Rev 10(1):25-44. https://doi.org/10.1016/S1053-4822(99)00037-6

Conklin MT, Lambert CU, Brenner M, Cranage DA (2009) Relationship of directors' beliefs of perceived organizational support and affective commitment to point in time of development of school wellness policies. J Foodserv Bus Res 12(2):110-119. https://doi.org/10.1080/15378020902910249

Crant JM (1996) The proactive personality scale as a predictor of entrepreneurial intentions. J Small Bus Manag 34(3):42-49

Cunningham GB, Ahn NY (2018) Moderation in sport management research: room for growth. Meas Phys Educ Exerc Sci 1-13. https://doi.org/10.1080/ 1091367X.2018.1472095

Dirks KT, Ferrin DL (2002) Trust in leadership: meta-analytic findings and implications for research and practice. J Appl Psychol 87(4):611-628. https:// doi.org/10.1037/0021-9010.87.4.611

Eisenberger R, Fasolo P, Davis-LaMastro V (1990) Perceived organizational support and employee diligence, commitment, and innovation. J Appl Psychol 75 (1):51-59. https://doi.org/10.1037/0021-9010.75.1.51
Eisenberger R, Huntington R, Hutchison S, Sowa D (1986) Perceived organizational support. J Appl Psychol 71(3):500-507

Graham JW (1991) An essay on organizational citizenship behavior. Empl Responsib Rights J 4(4):249-270. https://doi.org/10.1007/BF01385031

Grant GM (2000) Proactive behavior in organizations. J Manag 26(3):436-462

Greenglass ER (2002) Proactive coping and quality of life management. In: Frydenberg E (Ed.) Beyond coping: meeting goals, visions, and challenges. Oxford University Press, New York, pp. 37-62

Han TS, Chiang HH, Yang TC (2009) High commitment HRM, perceived organizational support, trust, and knowledge sharing: a multiple-level analysis. Manag Rev 28(1):25-44

Hayes AF (2009) Beyond Baron and Kenny: statistical mediation analysis in the new millennium. Commun Monogr 76(4):408-420. https://doi.org/10.1080/ 03637750903310360

Hayes AF, Scharkow M (2013) The relative trustworthiness of inferential tests of the indirect effect in statistical mediation analysis: does method really matter? Psychol Sci 24(10):1918-1927. https://doi.org/10.1177/0956797613480187

Hayes AF (2017) Introduction to mediation, moderation, and conditional process analysis: A regression-based approach. Guilford Publications

Hochwarter WA, Kacmar C, Perrewé PL, Johnson D (2003) Perceived organizational support as a mediator of the relationship between politics perceptions and work outcomes. J Vocat Behav 63(3):438-456. https://doi.org/10.1016/ S0001-8791(02)00048-9

House JS, Umberson D, Landis KR (1988) Structures and processes of social support. Annu Rev Sociol 14(1):293-318. https://doi.org/10.1146/annurev. so. 14.080188 .001453

Ji XL, Zeng Y, Ling L (2008) Relationship between perceived organizational support and staff performance. Ind Eng J 11(4):66-69

Kent A, Chelladurai P (2001) Perceived transformational leadership, organizational commitment, and citizenship behavior: a case study in intercollegiate athletics. J Sport Manag 15(2):135-159. https://doi.org/10.1123/jsm.15.2.135

Kim M, Kim ACH, Newman JI, Ferris GR, Perrewé PL (2018) The antecedents and consequences of positive organizational behavior: the role of psychological capital for promoting employee well-being in sport organizations. Sports Manag Rev 479:1-18

Li W, Wan W (2007) A demographic study on citizenship behavior as in-role orientation. Personal Individ Differ 42(2):225-234. https://doi.org/10.1016/j. paid.2006.06.014

Lin CW, Hu WH, Shih JB (2017) Does benevolent leadership always lead to organizational citizenship behavior? The mediated moderation effect of manipulative intention and trust. NTU Manag Rev 27(3):33-64. https://doi. org/10.6226/NTUMR.2017.JAN.A102-062

Lin HY, Lu L, Wu PY, Wu WY (2012) Are happy workers more productive? The dual influences of organizational support work attitudes. Chin J Psychol 54 (5):451-469

Lu WC, Kuo C-C (2016) Internship performance and satisfaction in sports: Application of the proactive motivation model. J Hosp Leis Sport Tour Educ 18:33-41. https://doi.org/10.1016/j.jhlste.2016.02.003

Love A, Kim S (2019) Organizational citizenship behavior in sport: a perspective from athletes. J Sport Manag 33(1):25-36. https://doi.org/10.1123/jsm.2018-0036

Miao MC, Shih CF (2013) The influence of workload and family demand on work-family conflict: the moderator of proactive personality. J Bus Manag 105:79-100

Moorman RH, Blakely GL, Niehoff BP (1998) Does perceived organizational support mediate the relationship between procedural justice and organizational citizenship behavior? Acad Manag J 41(3):351-357. https://doi.org/ $10.5465 / 256913$

Parker SK, Bindl UK, Strauss K (2010) Making things happen: a model of proactive motivation. J Manag 36(4):827-856. https://doi.org/10.1177/ 0149206310363732

Parker SK, Williams HM, Turner N (2006) Modeling the antecedents of proactive behavior at work. J Appl Psychol 91(3):636-652. https://doi.org/10.1037/ 0021-9010.91.3.636

Preacher KJ, Hayes AF (2004) SPSS and SAS procedures for estimating indirect effects in simple mediation models. Behav Res Methods Instrum Comput 36 (4):717-731. https://doi.org/10.3758/BF03206553

Rhoades L, Eisenberger R (2002) Perceived organizational support: a review of the literature. J Appl Psychol 87(4):698-714. https://doi.org/10.1037/00219010.87.4.698

Seibert SE, Crant JM, Kraimer ML (1999) Proactive personality and career success. J Appl Psychol 84(3):416-427

Seibert SE, Kraimer ML, Crant JM (2001) What do proactive people do? A model linking proactive personality and career success. Pers Psychol 54(4):845-874. https://doi.org/10.1111/j.1744-6570.2001.tb00234.x

Thompson JA (2005) Proactive personality and job performance: a social capital perspective. J Appl Psychol 90(5):1011-1017. https://doi.org/10.1037/00219010.90.5.1011 
Tian XM, Xie ZT, Zhu JL (2009) The impact of proactive personality on organizational citizenship behavior and team performance: examining a path model. J Hum Resour Manag 9(2):19-32. https://doi.org/10.6147/ JHRM.2009.0902.02

Viswesvaran C, Ones DS, Schmidt FL (1996) Comparative analysis of the reliability of job performance ratings. J Appl Psychol 81(5):557-574. https://doi.org/ 10.1037/0021-9010.81.5.557

Wayne SJ, Shore LM, Bommer WH, Tetrick LE (2002) The role of fair treatment and rewards in perceptions of organizational support and leader-member exchange. J Appl Psychol 87(3):590-598

Yeh LH, Lin WQ (2007) Proactive personality in industrial and organizational psychology. Adv Psychol Sci 15(3):498-504

\section{Acknowledgements}

This study was supported by the National Taipei University, Taiwan.

\section{Competing interests}

The authors declare no competing interests.

\section{Additional information}

Correspondence and requests for materials should be addressed to F.-J.W.
Reprints and permission information is available at http://www.nature.com/reprints

Publisher's note Springer Nature remains neutral with regard to jurisdictional claims in published maps and institutional affiliations.

(c) (i) Open Access This article is licensed under a Creative Common Attribution 4.0 International License, which permits use, sharing, adaptation, distribution and reproduction in any medium or format, as long as you give appropriate credit to the original author(s) and the source, provide a link to the Creative Commons license, and indicate if changes were made. The images or other third party material in this article are included in the article's Creative Commons license, unless indicated otherwise in a credit line to the material. If material is not included in the article's Creative Commons license and your intended use is not permitted by statutory regulation or exceeds the permitted use, you will need to obtain permission directly from the copyright holder. To view a copy of this license, visit http://creativecommons.org/ licenses/by/4.0/.

(c) The Author(s) 2020 